\title{
Treatment of leprosy in rural India as seen on a medical student elective
}

\author{
D N RILEY* \\ Christian Fellowship Community Health Centre, Ambilikkai, \\ Madurai District, Tamil Nadu
}

\begin{abstract}
Summary A personal report on the community and hospital treatment of leprosy in the rural villages of South India. Details are given of the present drug regimens and the practical difficulties encountered in implementing them successfully.
\end{abstract}

\section{Introduction}

I went to India on my elective from Birmingham University Medical School with the intention of seeing medicine practised in an underdeveloped country with limited resources, and with a different spectrum of disease. One of the diseases I particularly wanted to study was leprosy. I was armed with only a standard British medical student knowledge about leprosy, and a few mental pictures of 'what leprosy did to people' from various films, charity posters and books. I had a very privileged opportunity during my short stay to see the reality of leprosy treatment in rural India, as I was able to spend much of my time in the many small Indian villages, actually amongst the Indian people themselves, as well as seeing the hospital side of leprosy care.

Tamil Nadu is one of the high prevalence areas for leprosy in the Indian sub-continent. The areas of high prevalence, 10 per 1000 or more, are found mainly in the south-eastern parts of the country. This belt of high prevalence includes Tamil Nadu, Andhra Pradesh, Orissa, Pondicherry and the Lakshadweep Islands. Tamil Nadu is hyper-endemic for leprosy with an overall prevalence rate of 19 per 1000. Out of 15 districts in the State (excluding Madras City), 14 have a prevalence rate of 10 or more per 1000 which includes the Madurai District where I spent my elective.

The leprosy control programme of Tamil Nadu is based on either Government Leprosy Control Units or missionary-supported control programmes. The Christian Fellowship Community Health Centre at Ambilikkai is the headquarters for the Leprosy Control Programme for this part of Tamil Nadu. Although the hospital has grown and spread into many aspects of medicine, surgery, cancer and tuberculosis, it started originally in 1965 to treat leprosy patients. As a missionary control unit most of the money is received f rom voluntary organizations outside India.

The area covered by this control programme has a population of 1.34 lakh $(134,000)$, and is divided into 6 smaller areas, each controlled by 1 Leprosy Inspector (paramedical worker). This area has 40 main villages, or Panchat, each of which comprises 6 hamlets.

\section{Treatment}

I will deal with the hospital facilities first. The hospital has a leprosy ward of 53 beds, which at any

* Present address: The Medical School, University of Birmingham, England. 
given time seems to have about $70 \%$ bed occupancy. Patients are admitted for the treatment of severe ulcers and reactions, and the occasional tendon transplant operation. There is also a leprosy Rehabilitation Centre where patients learn weaving, shoe-making, carpentry, welding and agriculture. The hospital has a physiotherapist who has completed a 9-month governmentapproved course in physiotherapy for leprosy at Vellore C.M.C. The hospital also has its own facilities for making chappels, or sandals as we call them, suitable for the leprosy patients.

Being in the hospital one could easily be deceived that the leprosy work here is successful, and that all is going well. Patients presenting with newly-diagnosed leprosy receive skin smear tests and are started on the World Health Organization (WHO) recommended drugs for their particular type of leprosy. However, these drugs had only been available free for a few weeks. This limited supply of free rif ampicin and clofazimine (lamprene) has been made available by the Indian Government. Prior to that all patients were only receiving dapsone, unless they could afford to buy rif ampicin and clofazimine, which for the majority of these people because they are so poor is impossible.

However, the reality is that the patients attending the hospital out-patient department are only a small percentage of the total leprosy patients, and indeed many actually come from outside the control area. The majority of the leprosy patients never come to the hospital. They are suspected, diagnosed and treated in the villages and only if they develop severe reactions and ulcers are they referred to the hospital. It must, however, be remembered that referral to hospital, and actually coming to the hospital as an in-patient do not always follow on from each other, since many of the villagers will not pay the bus fare to the hospital or cannot afford to stop working and leave their families unsupported - there is no 'signing on the sick' in India.

Treatment for the vast majority of patients is only dapsone, irrespective of the type of leprosy diagnosed, and the general policy for treatment in the villages is as follows:

\begin{tabular}{|c|c|c|}
\hline $\begin{array}{l}\text { Dapsone } 100 \mathrm{mg} \text { daily } \\
\text { for } 3-4 \text { years }\end{array}$ & $\underset{\text { (negative smear) }}{\stackrel{\text { Clinically inactive }}{\longrightarrow}}$ & $\begin{array}{l}\text { dapsone } 50 \mathrm{mg} \text { daily } \\
\text { for } 10 \text { years or life. }\end{array}$ \\
\hline \multicolumn{3}{|l|}{ Borderline } \\
\hline $\begin{array}{l}\text { Dapsone } 100 \mathrm{mg} \text { daily } \\
\text { for } 18 \text { months }\end{array}$ & Clinically inactive & $\begin{array}{l}\text { dapsone } 50 \mathrm{mg} \text { daily } \\
\text { for } 7 \text { years. }\end{array}$ \\
\hline \multicolumn{3}{|l|}{ Tuberculoid } \\
\hline $\begin{array}{l}\text { Dapsone } 100 \mathrm{mg} \text { daily } \\
\text { for } 18 \text { months }\end{array}$ & Clinically inactive & $\begin{array}{l}\text { dapsone } 50 \mathrm{mg} \text { daily } \\
\text { for } 3 \text { years. }\end{array}$ \\
\hline
\end{tabular}

In the hospital the drug regimens are as follows:

\section{Multibacillary}

Rifampicin $600 \mathrm{mg} /$ month

Clofazimine $100 \mathrm{mg}$ t.d.s. for 1 week

Dapsone then $100 \mathrm{mg}$ alternate days $100 \mathrm{mg}$ daily

For 2 years or until

Bacteriological Index is negative

then dapsone $100 \mathrm{mg}$ daily; in case of lepromatous for 10 years; in case of borderline for 7 years. 


\section{Paucibacillary}

$\left.\begin{array}{ll}\text { Rifampicin } & 600 \mathrm{mg} / \mathrm{month} \\ \text { Clofazimine } & 100 \mathrm{mg} \text { t.d.s. for } 1 \text { week } \\ \text { then } 100 \mathrm{mg} \text { alternate days } & 100 \mathrm{mg} \text { daily }\end{array}\right\} \longrightarrow$ For 6 months

then dapsone $100 \mathrm{mg}$ daily for 5 years.

\section{Treatment of reactions}

The basic policy is 1 , admit; 2 , bed rest; 3 , analgesia; 4 , chloroquine; and 5, clofazimine, if not already taking it.

Steroids are used if swelling is excessive.

As already mentioned, most of the village people are only receiving dapsone for treatment of their leprosy, and it also became clear to me that many of these people are probably not even taking the dapsone. This is confirmed by a random survey of two Panchat carried out by one leprosy inspector from 15 April 1982 to 18 April 1983.

Panchat A: 25 cases detected in total. Of these: 7 (28\%) unregistered (i.e. no treatment); 12 (48\%) regular treatment; and $6(24 \%)$ irregular treatment.

Panchat B: 10 cases detected in total. Of these: $2(20 \%)$ unregistered; $5(50 \%)$ regular treatment; and $3(30 \%)$ irregular treatment.

In fact, in the whole of this particular area, with a population of 25,000 , there are 283 known cases of leprosy (LL, 36; BL, 44; T, 203): 68 (24\%) unregistered and hence no treatment; 135 (48\%) regular treatment; $80(28 \%)$ irregular treatment.

Hence the reality of leprosy treatment in rural India is as follows:

1 Most of the detected cases of leprosy are found by the leprosy inspectors. Studying their figures though, it is only practical for them to 'examine' $75 \%$ of their population because people may be in the fields or in other villages when they visit the house on their survey or may ref use to be examined. Examination of the women is a particularly cursory affair since only exposed skin can be examined. 2 Most of the newly-detected cases take treatment, but of the $20 \%$ who do not, they are usually of the low caste Harijans, who live in close proximity to contacts (often as many as 8 people in a small, one-roomed house), and in the most appalling unhygienic conditions with poor nutrition, i.e. conditions which are conducive to the continuing spread of an infectious disease.

3 Taking 'regular' treatment at this hospital means that the patient attends the mini-health centre for a monthly supply of dapsone at least 9 months a year. If there is work to do in the fields, or a festival or wedding to attend, they will not come for their drugs, although it is acceptable for the patient to receive the tablets by proxy. Also the prolonged course of treatment with dapsone means these people will soon stop coming for their dapsone, perhaps because they do not feel to be getting better, or the tablets make them feel unwell, or they simply do not understand the need for long-term regular treatment. The high illiteracy of India's population makes the last reason by far the most likely cause.

4 Even when patients do comply with treatment they are not receiving the best drugs available for their type of leprosy. The WHO recommendations of multitherapy for multibacillary cases and dapsone-resistant cases is not being carried out at present for the vast majority of patients. Indeed until 1982, patients with active leprosy were only receiving $50 \mathrm{mg}$ of dapsone daily. Only since early 1982 have newly-diagnosed patients been started on $100 \mathrm{mg}$ dapsone daily. Also prior to 1982 the maintenance dose was only $25 \mathrm{mg}$ dapsone daily. 
A summary of the treatment of leprosy in the leprosy control area based at the Christian Fellowship Community Health Centre, Ambilikkai, up to May 1983 is detailed below. The classification used at the hospital is that stipulated by the Tamil Nadu Government.

L, Lepromatous; N, Tuberculoid; N?L, Borderline and Indeterminate.

Total population, 130,000

Total number of known leprosy cases, 1913

Cases regarded as being active leprosy, $1365(70 \%)$

Prevalence of leprosy $14 \cdot 7$ per 1000 population.

$\begin{array}{llll}\mathrm{L} & \mathrm{N} & \mathrm{N} ? \mathrm{~L} \\ 240(13 \%) & 1227(64 \%) & 446(23 \%) & 1913(100 \%)\end{array}$

At the end of April 1983, 1461 were registered for treatment.

$$
\begin{array}{llll}
\mathrm{L} & \mathrm{N} & \mathrm{N} ? \mathrm{~L} & \\
191 & 940 & 330 & 1461(76 \%)
\end{array}
$$

Total number of patients who actually took treatment was 1,013 .

\begin{tabular}{lrrrr} 
& $\mathrm{L}$ & \multicolumn{1}{c}{$\mathrm{N}$} & $\mathrm{N} ? \mathrm{~L}$ & \\
Clinic & 152 & 587 & 260 & 999 \\
Domiciliary & 8 & 2 & 4 & 14 \\
& & & & $1013(53 \%)$
\end{tabular}

Clearly from the above figures, only just over half the detected leprosy patients are taking regular treatment, and this is an area with a well-organized leprosy control programme.

\section{DRUG RESISTANCE}

Resistance to dapsone is the only important drug resistance seen in this part of India. Resistance to rif ampicin and clofazimine is not encountered simply because the use of these drugs at present is negligible. Drug resistance is diagnosed clinically by the patient failing to respond to dapsone monotherapy despite taking regular treatment, or developing new signs and symptoms of leprosy after showing initial improvement. Where skin smears are performed then failure of the Bacteriological Index to fall is taken as supportive evidence. To prove dapsone resistance in the mouse footpad is clearly not practical.

When a patient has failed to improve, or relapses af ter dapsone treatment, they are watched more closely by the leprosy inspector for a further 6 months, and encouraged to take regular treatment if they are not already doing so. If there is still no improvement they are regarded as being resistant to dapsone. However, since multitherapy is not available then the diagnosis is academic, in so far as the treatment continues at $100 \mathrm{mg}$ daily. There is an overall figure of 17 suspected dapsone-resistant cases for this leprosy control area, all of which are thought to be secondary dapsone resistance. This gives a prevalence of 12.5 resistant cases per 1000 active cases.

It is a sad reality that these resistant cases are not able to attend the hospital for multitherapy for a variety of reasons. With the recently available rif ampicin and clofazimine they could be treated free, or with a nominal charge. The two main reasons they will not attend are illiteracy and cost. It becomes very difficult to explain to illiterate people, who probably do not even understand the basics of their disease, the concepts of resistance and the need for different medicine. Not only do the people fail to understand why they must go to the hospital, they also see that it will cost money. In the hierarchy of personal needs, health takes a low priority in a poor person. Consequently these people are still in the villages receiving only $100 \mathrm{mg}$ dapsone daily. To illustrate the cost problem, an 
average poor man earns Rs $5 /-$ daily $(£ 1=\mathrm{Rs} 15 /-)$; bus fares are approximately Rs $2 /-$ to the hospital from a village, and one $150 \mathrm{mg}$ rifampicin tablet costs $\mathrm{Rs} 4 /-$.

Commencing later this year is a plan to bring rif ampicin and clofazimine to most of the patients who require it, i.e. multibacillary and resistant cases, which at the present time is 160 patients. This has been made possible by the donation of funds from American Leprosy Mission and WHO through the Indian Government. The plan is that all patients who are multibacillary or resistant cases and are regular attenders, will receive rifampicin and clofazimine according to a slightly modified WHO regimen. Since the supply of money and drugs will be limited it is felt only those patients who are known to be compliant can have multitherapy initially. The leprosy inspectors will receive monthly supplies of these drugs for patients in their area from the hospital and will take the drugs to the individual patients once a month, making sure they 'put the tablets in their mouths and swallow them'. The WHO recommendation for clofazimine will be modified to $300 \mathrm{mg}$ monthly, with no alternate daily dosage, because of the extra expense and the problem of supervising patient compliance. Rif ampicin will be given $600 \mathrm{mg}$ once monthly with the clof azimine. Indeterminate and tuberculoid types will continue to be treated with dapsone monotherapy because of the limited resources. It remains to be seen how well this plan will work and whether or not sufficient drugs will be available.

\section{Discussion}

The reasons why patients in the rural parts of India do not come forward with their leprosy, or ref use treatment, are complex, but are undoubtedly founded in illiteracy and poverty. More than $60 \%$ of India's population is still officially regarded as being illiterate, with a higher percentage in rural Indian villages. Seventy per cent of the population live in India's 600,000 mud-hut villages. Since the population of India is now in excess of 750,000,000 people, this means 525,000,000 people are living in rural India where medical services are at best poor. India has still not found a way to get its doctors into those areas where need is greatest, and the majority still work in the large cities and towns.

Some of the reasons which contribute to the failure of leprosy treatment at the present time are:

1 Ignorance; not only about leprosy, but disease in general. The reason most patients make their initial cancer presentation with secondaries, and diabetics present with the most awf ul deep infected ulcers, and tuberculosis patients present with only a small percentage of their total lung capacity functioning, are all illustrations of the ignorance and illiteracy of these people. Ignorance of leprosy is just part of this picture.

2 Social stigma; still a very real problem and one which again will take many years to change. Even when cured the signs of leprosy still make it very difficult for these people to be accepted back into society, and their families are regarded as being cursed by other members of the village.

3 The disease itself; leprosy in its early stages has none of the symptoms which normally bring these people to a doctor, such as pain, bleeding, vomiting, dyspnoea and coughing. Also many of the people are aware that a leprosy patch may self-heal, and so may delay in presenting.

4 Long treatment; which initially may not make their leprosy improve, indeed may have undesirable side-effects, and which they fear may cost money.

There are a number of positive aspects to the leprosy control programme in this part of Tamil Nadu. The system of survey, education and treatment, centred on the leprosy inspectors, is working well and people are being detected early in their disease. Treatment for these people is available locally if they attend. Also there is a hospital with good facilities for treating the complications of leprosy and for the rehabilitation of leprosy patients. Leprosy education through the leprosy inspectors, leprosy dramas (acted by staff and students from the hospital in a different village each month), and village 
leaders is also having some success. I was shown some reliable figures to illustrate that in one village where intensive leprosy education had been carried out the uptake of regular treatment had increased from $38 \%$ to $60 \%$, which is encouraging but still leaves a long way to go.

The effect of the leprosy care in this part of South India during the past 15 years is illustrated in the following figures: 1968, prevalence of 20 per 1000 population; 1979, 17 per 1000; 1982, 15 per 1000. The prevalence of leprosy in this area shows a fall of 5 per 1000 population, but the population has increased by nearly 5000 in these 14 years, to its present level of 130,000. Assuming a similar rate of fall, and no significant change in the population, it will be at least another 35 years before leprosy is eradicated in this area with the present system. Unfortunately the feeling expressed to me whilst I was in India is that this fall has been due to changing factors which were readily accessible to change, but to go from $15 / 1000$ to complete eradication will mean altering factors which are much less accessible. For example, this will mean improving an illiteracy rate of $60 \%$; improving unhygienic conditions, nutrition and living standards, which are at present appalling; changing many centuries of culture and religion which misguidedly makes an Indian with disease go to a temple before going to a doctor.

The Prime Minister of India, Mrs Indira Ghandi, tried to promote leprosy to a respectable level by expressing personal interest in the disease, and coined the slogan, "leprosy eradication by the year 2000'. To indicate her seriousness she constituted a high powered committee to draw up an action plan to implement the programme. Sadly the vast size of India often means that when the Central Indian Government sets up such a plan, the help rarely reaches the people it is intended for. In a country which is still so underdeveloped, not even being able to supply clean water to the majority of its population, and indeed whilst I was in India many parts had no water at all due to failure of the monsoons, then the treatment of leprosy must be well down the list of priorities of the Indian Government, whatever the official policy may be. Undoubtedly finance is a major problem, and India is at present incapable of providing it, with so many other more important priorities. Hence the availability of foreign aid for leprosy programmes is essential. Nevertheless, we must acknowledge that however much money is made available to buy drugs and improve care, it will only be of benefit when the average Indian villager with leprosy has been educated sufficiently to understand his disease and the need to take treatment.

The spread of communicable diseases in Western countries, including leprosy, declined by improving these very factors listed above, together with the introduction of vaccines and drugs. Hence it would seem that the treatment of leprosy in India will only be successful in the long term if there is a general improvement in the standard of living and nutrition as well as the administration of the correct drugs.

\section{Acknowledgements}

It is with sincere gratitude that I thank LEPRA for their financial help which made my visit to India possible. My thanks also go to Dr J Cherian, Director of the Christian Fellowship Community Health Centre, for allowing me complete freedom to study the care of leprosy in his hospital and in the associated community health schemes. 